\title{
OCCUPATIONAL RISK FACTORS IN SMALL STOCKBREEDING FARMS INCLUDING LITHUANIAN CONDITIONS
}

\author{
Ricardas Butkus, Gediminas Vasiliauskas \\ Aleksandras Stulginskis University, Lithuania \\ ricardas.butkus@asu.lt, gediminas.vasiliauskas@asu.lt
}

\begin{abstract}
Animal husbandry is one of the agricultural sub-sectors, which might have negative influence on human health and has a vast number of occupational risk factors on workers. As small (family) animal husbandry farms (up to 50 cows) are prevailing in Lithuania and consist $\sim 67 \%$ of the total number, special attention should be focused on the reduction of occupational risk factors in such farms, as they have a significantly higher risk level because of lack of resources and safety culture. The aim of this article is to identify and assess the prevailing occupational risk factors in such stockbreeding farms in Lithuania.Most common risk factors include dust, thermal environment, noise, ergonomic and physical load factors as well as biological risks. It was found that noise level during breeding and automated distribution of forage might be as high as $87.3 \mathrm{~dB}(\mathrm{~A})$, while concentration of particulate matters (PM10) might reach the value of $2.2 \mathrm{mg} \cdot \mathrm{m}^{-3} \mathrm{during}$ the manual distribution flour in the cowshed. Thermal environment in small cowsheds is within 7 and 12 degrees while the humidity of air might reach $90 \%$, which can be attributed as unfavourable working conditions. As most works in such farms are done manually, parameters of physical activity were collected during milking, manual manure removal and feeding operations. Maximum physical loads were found for manual feeding (pulse value of 135 pulses per minute), manual manure removal to the scraper (120 pulses per minute). Such works are attributed as very hard physical labour.
\end{abstract}

Keywords: dust, microclimate, noise, physical load, stockbreeding.

\section{Introduction}

Agriculture is a major economic activity in the EU and Lithuania and employs 25 million and $\sim 350000$ workers respectively [1].According to the data provided by Eurostat, more than half of these agricultural workers $(53 \%)$ were working on farms with a small economic size, while farms with only family workers ( $100 \%$ of the labour input on the farm was provided by family members) accounted for $93,7 \%$ of the total number of farms in the EU-28 in 2013 [1]. For the case of Lithuania, small family farms are dominant and the average size of the farm is 9.37 ha compared to 16,1 ha for the EU-28 $[1 ; 2]$. These farms are usually poorly specialized and prosecute multiple activities as well as usually lack safety culture because of limited resources.

According to the data provided by the Agricultural Information and Rural Business Centre [2] there were 120000 farms registered in Lithuania in 2016, while small cow farms were dominant (Fig. 1). These data show that more than $80 \%$ of all cow keepers keep from 1 to 5 cows in Lithuania but only approximately $30 \%$ of all cows are kept in such farms. According to statistical data, largest percentage, i.e. $38 \%$ of cows are kept in the farms of size 6-50 cows, while additional $30 \%$ in the farms with more than 50 cows [2].

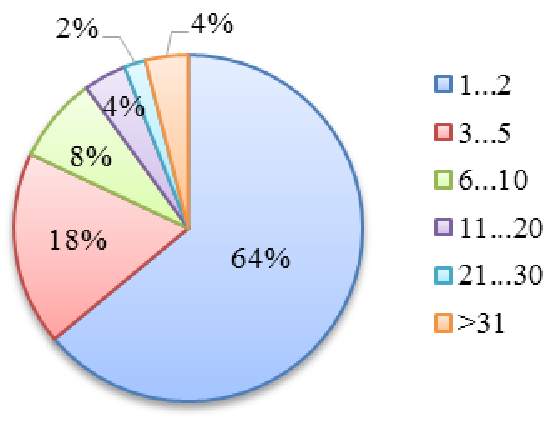

Fig. 1. Distribution of cattle keepers by the number of cows in Lithuanian farms

Agriculture is the sector, which includes the largest number of risk factors, which strongly depend on the type of agricultural production while dairy farming is attributed as a hazardous activity. The environmental factors most frequently accompanying stockbreeding farm workers are various gases, 
dust, microclimatic conditions, physical stresses, influence of noise from equipment and animals. Analysis of these risk factors is of great importance, as the agricultural sector includes young and elderly workers, which are generally of greater sensitivity to risk.

Various researchers provide evidence about the presence and effect of risk factors, while Malocznik revealed that farmers' average exposure time to these above mentioned factors can be about $51 \%$ of the total working time on a farm in the group of plant producers; $80 \%$-among animal breeders; and $77 \%$ - among farmers engaged in mixed production [3]. Dairy farming usually includes vast of manual works, which can demand difficult working postures and movements, repetitive and monotonous work tasks and therefore associated with various injuries. As reported by Kolstrup, the most frequently reported health problems caused by physical work for farmers and farm workers are located in the lower back (50\% and $43 \%$, respectively) and the shoulders (47\% and $43 \%$, respectively) [4].

Dairy farm workers are also under the moderate or even high exposure to organic dust, which suggests that such exposure over many years could be a major risk factor for the development of chronic obstructive pulmonary disease in dairy farmers [5]. Respiratory disorders develop from inhalation of grain dust, other types of organic dusts, and work in animal confinement facilities. These pollutants arise from manure, dry feedings, bedding materials and the animals and mostly depend on the deficiencies in the building design and operation. Organic dusts are also of primary concern as might have negative effects on human health [5].

Assessment of the dust is done using three criteria for biologically-relevant size-selective aerosol sampling of workers exposed to hazardous dust in industrial situations defined by ISO: respirable dust, thoracic dust and inhalable dust [6].Health effects of dust are closely associated with the concentration of the dust fraction up to $10 \mu \mathrm{m}$ (PM10) and to $2.5 \mu \mathrm{m}$ (PM2,5), i.e. particulate matter sampled through an inlet with a $50 \%$ cut-off at $10 \mu \mathrm{m}$ and $2.5 \mu \mathrm{m}$, respectively [7]. Seedorf and Hartung [8] provided the results of the dust concentrations in cowsheds. They found that the inhalable dust fraction concentration in the cowshed might reach $1.22 \mathrm{mg} \cdot \mathrm{m}^{-3}$, while the respirable particulate fraction $0.17 \mathrm{mg} \cdot \mathrm{m}^{-3}$. Barrasa et al. also investigated the exposure of workers to carbon dioxide $\left(\mathrm{CO}_{2}\right)$, ammonia $\left(\mathrm{NH}_{3}\right)$ and hydrogensulfide $\left(\mathrm{H}_{2} \mathrm{~S}\right)$. Significant differences were observedbetween hourly $\mathrm{CO}_{2}$ concentrations, depending on the activities inside the building. However, it was found that the values of daily exposure and short-term exposure toNH $\mathrm{H}_{3}, \mathrm{H}_{2} \mathrm{~S}$ and $\mathrm{CO}_{2}$ were below the corresponding exposurelimit values in all cases [9].

Farmers and other farm workers are also usually exposed to noise of high levels, which can reach $90 \mathrm{~dB}(\mathrm{~A})$ during milking, while in the hearing zone of the animals' the noise level can be 70$80 \mathrm{~dB}(\mathrm{~A})$, feeding installations might emit sound level of up to $83.0 \mathrm{~dB}(\mathrm{~A})$ [10]. Similar results of increased noise risk on farm workers was demonstrated by Solecki, where the calculated mean equivalent daily exposure to noise for the whole year was $90.5 \mathrm{~dB}(\mathrm{~A})$ for farms of mixed production and slightly lower for animal breeding farms [11].Noise levels strongly depend on the processes and equipment used in farms.

The results of these studies show the necessity to evaluate the risks arising from agricultural activities, especially from stockbreeding, which could help improve the risk assessment process and safety management in farms. In this paper, we present multiple aspects concerning the health risks associated with dairy farming and what measures should be taken to protect human health. The aim of the research was to identify and assess the prevailing occupational risk factors in stockbreeding farms in Lithuania.

\section{Materials and methods}

The research was carried out in 5 typical farms for Lithuania of a different size. Two of them were farms (50 and 80 cows) where all operations are done manually, 3 were semi-automated, i.e. feeding of the cows is performed using the feed mixer, which moves along the cowshed on the feeding lane. Milking in these farms is also semi-automated as well as manure removal.

Noise level measurements and exposure calculations were carried out according to the requirements of the international standards ISO 9612:2009 [12] and ISO 1999:2004 [13].Noise level measurements were done by using the first-class sound pressure level meters DELTA OHM HD-2010 
and Bruel\&Kjaer 2270. Parameters, such as continuous equivalent A-weighted sound pressure level $\left(L_{A, e q}\right)$, equivalent $\mathrm{C}$-weighted sound pressure $\left(L_{C, e q}\right)$, peak C-weighted sound pressure level $\left(L_{C, p e a k}\right)$ and $1 / 1$ octave frequency band spectrums were measured.

Position of the measurement microphone was at the operator ear level approx. $100 \mathrm{~mm}$ from the ear. Duration of the noise level measurements was at least $60 \mathrm{~s}$ and the measurements were repeated three times.

The EU Directive 2003/10/EC [14] regulates the minimum health and safety requirements to workers arising from noise. Limit values and exposure action values in respect of the daily noise exposure levels $\left(\mathrm{L}_{E X, 8 h}\right)$ and the peak sound pressure are fixed at:

1. Peak sound pressure $\left(p_{\text {peak }}\right)$ : maximum value of the $\mathrm{C}$-weighted instantaneous noise pressure;

2. Daily noise exposure level $\left(L_{E X, 8 h}\right)$ for a nominal eight-hour working day as defined by the ISO 1999:2013 [13];

3. Weekly noise exposure level as a time-weighted average of the daily noise exposure levels for five working days as defined by the ISO 1999:2013.

The exposure limit values and exposure action values in respect of the daily noise exposure levels and the peak sound pressure are fixed at:

1. exposure limit values: $L_{E X, 8 \mathrm{~h}}=87 \mathrm{dBA}$ and $p_{\text {peak }}=200 \mathrm{~Pa}$ (or $L_{\text {Cpeak }}=140 \mathrm{dBC}$ );

2. upper exposure action values: $L_{E X, 8 \mathrm{~h}}=85 \mathrm{dBA}$ and $p_{\text {peak }}=140 \mathrm{~Pa}\left(\right.$ or $L_{\text {Cpeak }}=137 \mathrm{dBC}$ );

3. lower exposure action values: $L_{E X, 8 \mathrm{~h}}=80 \mathrm{dBA}$ and $p_{\text {peak }}=120 \mathrm{~Pa}$ (or $L_{\text {Cpeak }}=135 \mathrm{dBC}$ ).

If the worker (operator) is exposed to noise less than eight hours per day and the noise level changes tangibly at different time periods, the A-weighted sound pressure level can be calculated as the output of the working time and noise level over the time period $T_{e}[12]$ :

$$
L_{A, e q, T e}=10 \lg \left[\frac{1}{T_{e}} \sum_{i=1}^{n} t_{i} \cdot 10^{0,1 L_{A e q, i}}\right], \mathrm{dBA},
$$

where $L_{\text {Aeq,ti }}$-equivalent A-weighted sound pressure level over the measurement period $t_{i}$; $i$ - number of measurement intervals. Overall duration $t_{i}$ of the intervals is $T_{e}$.

Daily noise exposure of 8 hours is calculated as follows:

$$
L_{E X, 8 h}=L_{\text {Aeq, }, e}+10 \lg \left(\frac{T_{e}}{T_{0}}\right), \mathrm{dBA},
$$

where $L_{A e q, T e}-$ measured A-weighted sound pressure level over particular time period $T_{e}$;

$T_{0}$ - reference duration of 8 working hours. Dimensions $T_{0}$ and $T_{e}$ have the same dimensions (hours, minutes, seconds).

Dust concentration was measured using the particle counter TSI 8520 DustTrak. This analyser enabled to measure the concentration of dust of various particle size, i.e. to $10.0 \mu \mathrm{m}$; to $2.5 \mu \mathrm{m}$; to $1.0 \mu \mathrm{m}$ of size. During this research, the particle sizes were limited to $10 \mu \mathrm{m}$ (PM10). Particle counting was done using the Fluke 983 analyser, which can give the histogram of 6 particle sizes: smaller than $0.3 \mu \mathrm{m} ; 0.3-0.5 \mu \mathrm{m} ; 0.5-1.0 \mu \mathrm{m} ; 1.0-2.0 \mu \mathrm{m} ; 2.0-5.0 \mu \mathrm{m}$ and $5.0-10.0 \mu \mathrm{m}$ ) in particular volume of air (1 litre).

Concentration of dust and particle counting measurements were done at the workplace of the worker, 0,5 meter behind the face at the nose level. The measurements were done at three measuring points across the feeding lane in the cowshed. Dust concentration measurements were carried out during animal feeding. The measurements were repeated three times with the duration of minimum 1 minute for sampling [13]. Environmental parameters were measured using the meter Fluke 983.

Microclimate parameters (indoor air velocity) were measured using thermo-anemometer Testo 415 , while relative humidity by using the aspiration psychrometer. The measurements were carried out following the requirements for industrial buildings, i.e. at the beginning, middle and end of the day. Temperature and air velocity measurements were carried out in three horizontal planes at the heights of $0.1 \mathrm{~m}, 1.1 \mathrm{~m}$ ir $1.7 \mathrm{~m}$ from the horizontal floor plane. 
Physical load of workers was measured using the heart rate acquisition during various works. Heart rates were monitored using the heart rate monitor watches POLAR M32 and ASUS VivoWatch. ASUS VivoWatch can monitor average heart rate, heart rate time monitoring, steps and calorie usage. Heart rate monitors consist of timers and heart rate sensors. Measurement error of the POLAR M32 is $\pm 1 \%$. Heartrate of the worker was monitored at the beginning of each task in 5 minute intervals, when the total duration of heart rate measurements was 30 minutes.

\section{Results and discussion}

The data of the noise level and dust concentration measurements and typical working durations over the reference 8 hour working shift are given in Table 1.

Table 1

Results of the noise level and dust concentration measurements in dairy farms

\begin{tabular}{|l|c|c|c|c|c|}
\hline \multirow{2}{*}{$\begin{array}{c}\text { Measurement points(work } \\
\text { options) }\end{array}$} & Operator & $\begin{array}{c}\text { S weighted } \\
\mathrm{L}_{\mathrm{A}, \mathrm{eq}}, \mathrm{dBA}\end{array}$ & $\begin{array}{c}\text { C weighted } \\
\mathrm{L}_{\mathrm{C}, \mathrm{peak}} \mathrm{dBC}\end{array}$ & $\begin{array}{c}\text { Workdurat } \\
\text { ion in } \\
\text { minutes }\end{array}$ & $\begin{array}{c}\text { PM10 } \\
\text { concentrati } \\
\text { on } \mathbf{~ m g} \cdot \mathbf{m}^{-3}\end{array}$ \\
\hline 1. In tractor cab outdoors & Tractor driver & $84.3 \pm 0.2$ & $107.9 \pm 0.9$ & 60 & $0.31 \pm 0.11$ \\
\hline $\begin{array}{l}\text { 2. In tractor cab inside the } \\
\text { cowshed }\end{array}$ & Tractor driver & $85.7 \pm 0.9$ & $113.3 \pm 0.8$ & 60 & $0.29 \pm 0.07$ \\
\hline $\begin{array}{l}\text { 3.In the premise of } \\
\text { thegrainmill }\end{array}$ & Worker & $87.3 \pm 1.8$ & $108.6 \pm 1.4$ & 30 & $55.0 \pm 16.0$ \\
\hline $\begin{array}{l}\text { 4. Mechanizeddistribution } \\
\text { of forage in cowshed }\end{array}$ & Worker & $85.5 \pm 2.5$ & $111.2 \pm 0.6$ & 40 & $0.26 \pm 0.05$ \\
\hline $\begin{array}{l}\text { 5. Hand distribution of hay } \\
\text { in cowshed }\end{array}$ & Worker & $64.2 \pm 0.9$ & $96.0 \pm 1.8$ & 60 & $0.52 \pm 0.26$ \\
\hline $\begin{array}{l}\text { 6. Hand distribution of feed- } \\
\text { flour in cowshed }\end{array}$ & Worker & $62.1 \pm 1.2$ & $98.5 \pm 1.0$ & 60 & $2.20 \pm 0.52$ \\
\hline $\begin{array}{l}\text { 7. Mechanizeddistribution } \\
\text { of forage in field }\end{array}$ & Worker & $84.7 \pm 0.4$ & $110.3 \pm 0.6$ & 20 & $0.21 \pm 0.03$ \\
\hline 8. At the silage storage & Worker & $75.1 \pm 5.2$ & $99.2 \pm 4.2$ & 60 & $0.17 \pm 0.02$ \\
\hline
\end{tabular}

These results show, if the farm worker is under the influence of noise for approx. 3 hrs. per day, the daily noise exposure level $L_{E X, 8 h}$ might be as high as $82.6 \mathrm{~dB}(\mathrm{~A})$ and it exceeds the lower exposure value. Noise level logging was also used for the analysis of the noise during typical operations, feeding, preparation for milking and milking (total duration of 2 hrs.) (see Figure 2).

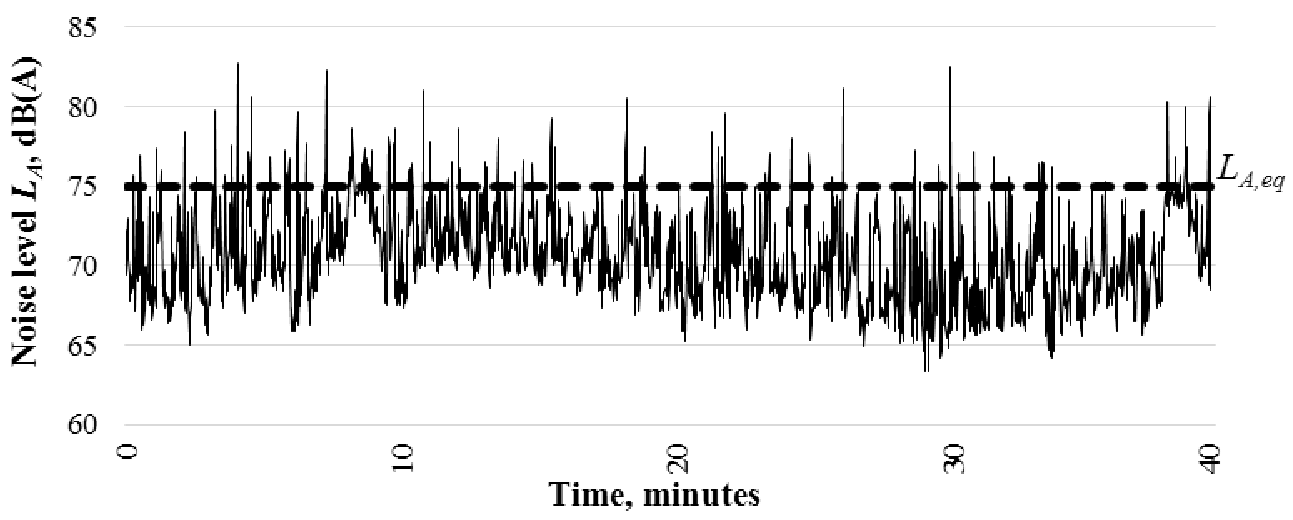

Fig. 2. Results of noise level logging in cowshed during milking period

These data show that the noise level during milking was less than the exposure lower value while the equivalent level $L_{A, e q}=74.9 \mathrm{~dB}(\mathrm{~A})$. The levels of milking operation are also significantly higher than those for preparation works. However, the measurement data show that time periods with noise levels, higher than $80.0 \mathrm{~dB}(\mathrm{~A})$, which is the exposure lower value, consist of only insignificant 
duration of time ( $L_{A, e q} \geq 80.0 \mathrm{~dB}(\mathrm{~A})$ logged only $1 \%$ of total time), therefore, it should not have any negative consequences on workers over the reference 8 hour work shift.

The measurement results of the dust concentration are presented in Figure 3. Concentrations and particle count strongly depend on operation. In a premise of a grain mill the concentration of the organic dust was $55 \pm 21 \mathrm{mg} \cdot \mathrm{m}^{-3}$, which is approximately ten times above the safe limit for organic dust (for a long-term exposure limit for inhalable fraction). The measured values during the distribution of hay and feed-flour did not exceed the limit value of $5 \mathrm{mg} \cdot \mathrm{m}^{-3}$ for organic dust, but for some individual cases it exceeded the value of $10 \mathrm{mg} \cdot \mathrm{m}^{-3}$. As seen in Figure 3, organic dust consists mostly of the particles, which are less than $1 \mu \mathrm{m}$ in diameter, which is unacceptable for a long-term exposure and might be the cause of asthma, asthma like syndromes, chronic bronchitis, hypersensitivity pneumonitis (Farmer's lung). These results are slightly higher if compared to those found by Seedorfand Hartung $\left(1.22 \mathrm{mg} \cdot \mathrm{m}^{-3}\right)$ [8] and much higher than reported by Kaasik and Maasikmets [15] and Jacobson et al. [16], where they report mean PM concentration in loose housing dairy farms of $0.21 \mathrm{mg} \cdot \mathrm{m}^{-3}$ with a range from 0.13 to $0.31 \mathrm{mg} \cdot \mathrm{m}^{-3}$. These differences are mainly caused because of mechanized feeding of dry feeds in comparison to background dust concentrations.

a)

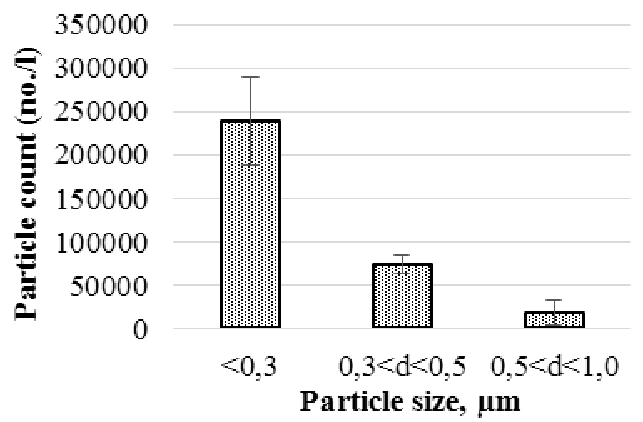

b)

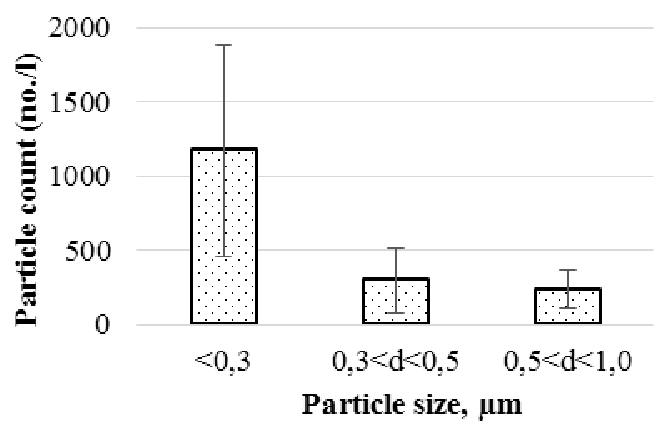

Fig. 3. Distribution of dust particles by size (d) in the grainmill premise (a) and in cowshed(b)

The microclimate parameters over the winter period showed that the temperature in the cowsheds was on average $10 \pm 2.5^{\circ} \mathrm{C}$. These results depend strongly on the construction of the cowshed and are lower for the buildings equipped with ventilation (natural or forced). Such temperature might be attributed as favourable for animals but unfavourable for workers as it was lower than the temperature required for the works requiring medium physical labour. The temperature measurement results are inter-related to the measurement data of the air velocity. These results show that greatest speeds were at the heights of $0.1 \mathrm{~m}\left(0.09 \mathrm{~m} \cdot \mathrm{s}^{-1}\right)$, while slightly lower at $1.7 \mathrm{~m}\left(0.05 \mathrm{~m} \cdot \mathrm{s}^{-1}\right)$. Such air velocities do not have any negative effect on human health. Additionally, to air velocity measurements, relative humidity was measured in every point. Relative air humidity was $90 \%$ on average, which can be in most cases attributed as too high.

For the analysis of physical labour needed for various operations, monitoring of heart rate was carried out. The experimental data of manual feeding, manure removal and milking are given in Figure 4. All working operations were analysed for a reference duration of thirty minutes and average heart rate was measured. According to Kristensen [17], milking and manual handling of milk reservoirs in semi-automated cowsheds can be attributed as light work, as the energy demand for such work is to $300 \mathrm{~W}$, while the manual distribution of hay or manure removal requires approx. $580 \mathrm{~W}$, which is hard physical labour (515-700 W).

The greatest physical loads on workers were found during manual feeding operations. Heart rate during this operation might reach $135 \mathrm{bpm}$, which is attributed as hard physical labour [17]. Slightly lower heart rate (to approx. $120 \mathrm{bpm}$ ) can be reached for manual manure removal.As seen in Figure 4, heart rate for milking was significantly less than for manure removal and feeding. However, this work includes strained postures and repetitive movements as well as manual handling operations, which, according to Jungbluth, might consist up to almost 50percent of works in farm [18]. Analysis of the milking process also showed that physical labour required for automated and semi-automated milking systems is by 20 percent less than for manual operations. Such systems also reduce the duration of 
milking operations, i.e. duration of preparation for milking and milking processes reduce by 15 percent for automated and manual milking respectively. These results are similar to those obtained by Kolstrup[4], where it was reported that milking is weak or moderate work, while health effects of any other work requiring physical labor can be reduced by shortening the duration and alternating various tasks.

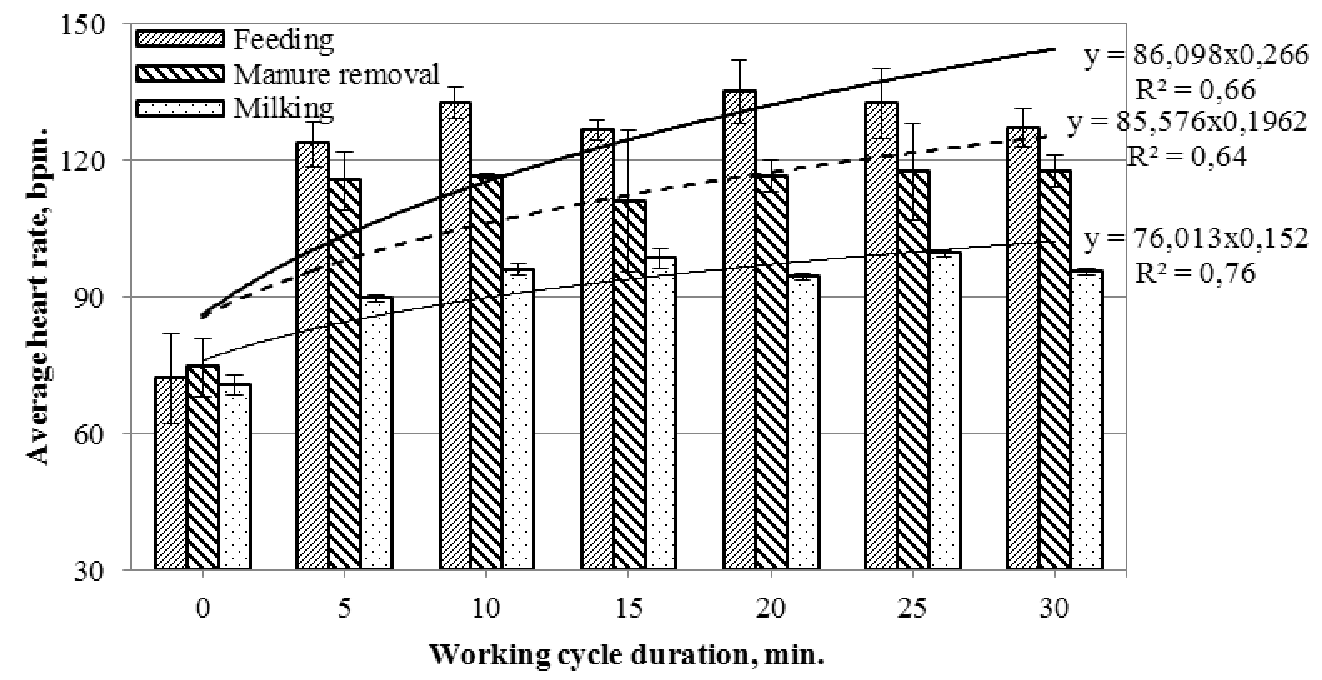

Fig. 4. Average heart rate of feeding, milking and manure removal works

\section{Conclusions}

1. Noise level in cowsheds during mechanized distribution of forage might reach the value of 85.5 $\mathrm{dB}(\mathrm{A})$.The most significant effect and exposure to noise is from milking operations, which are relatively long in duration and have the equivalent noise level $L_{A, e q}=74.9 \mathrm{~dB}(\mathrm{~A})$. The eight hour exposure lower value of $L_{E X, 8 h}=80.0 \mathrm{~dB}(\mathrm{~A})$ was not exceeded for these farm works.

2. Physical loads on workers tend to increase over the working cycle and are the highest for manual feeding operations. Average heart rates for manual feeding can reach 135 beats per minute and for manual manure removal -120 beats per minute. Such works are attributed as very hard physical labour.

3. The organic dust concentration in cowsheds might be exceeded when dry-forage is distributed or prepared. Particles with the diameter of less than $1 \mu \mathrm{m}$ consist more than 90 percent of the total count, while the concentration for manual distribution of forage might be $2.2 \mathrm{mg} \cdot \mathrm{m}^{-3}$.

4. Thermal environment in the investigated cowsheds was within 7 and 12 degrees in the winter period, the air velocity less than $0.1 \mathrm{~m} \cdot \mathrm{s}^{-1}$, while the relative air humidity $90 \%$ on average.

\section{References}

1. EU commission report. How many people work in agriculture in the European Union? [online] [10-03-2017]. Available at: http://ec.europa.eu/agriculture/sites/agriculture/files/rural-areaeconomics/briefs/pdf/08_en.pdf

2. Lietuvosžemèsūkis. Faktai ir skaičiai 2016. (Lithuanian Agriculture. Facts \& Figures 2016) (in Lithuanian). [online] [15-02-2017]. Available at: https://www.vic.lt/publication.php?id=23562

3. Malocznik A. Time of farmers'exposure to biological factors in agriculture working environment. Ann Agric Environ Med., vol. 11, 2004, pp. 85-89.

4. Kolstrup, C. L. Work-related musculoskeletal discomfort of dairy farmers and employed workers. Journal of Occupational Medicine and Toxicology (London, England), 7:23.

5. Cathomas R. L., Brüesch H., Fehr R., Reinhart W. H., Kuhn M. Organic dust exposure in dairy farmers in an alpine region. Swiss Med Wkly.132(13-14), 2002, pp. 174-178.

6. EN 481:1993. Workplace atmospheres - Size fraction definitions for measurement of airborne particles.

7. Dolejš J., Mašata O., Toufar O. Elimination of dust production from stables for dairy cows, Czech J. Anim. Sci., 51, 2006 (7), pp. 305-310. 
8. Seedorf J., Hartung J. Emission of Airborne Particulates from Animal Production. [online] [1003-2017]. Available at: http://www.agriculture.de/acms1/conf6/ws4dust.htm.

9. Barrasa, M,LLamosa, S., Fernandez, M. D., Fernandez, E. Occupational exposure to carbon dioxide, ammonia and hydrogen sulphide on livestock farms in north-west Spain. Ann Agric Environ Med. 2012;19(1), pp. 17-24.

10. Algers B., Ekesbo I., Stromberg S. Noise measurements in farm animal environments. Acta VeterinariaScandinavica, Iss. 68 (suppl.), 1978, pp. 1-19.

11. Solecki L. Evaluation of annual exposure to noise among private farmers on selected family farms of animal production profile. Ann Agric Environ Med, Iss. 12, 2005, pp. 67-73.

12. ISO 9612:2009 Acoustics - Determination of occupational noise exposure - Engineering method.

13. ISO 1999:2013. Acoustics - Estimation of noise-induced hearing loss

14. Directive 2003/10/EC of the European Parliament and of the Council of 6 February 2003 on the minimum health and safety requirements regarding the exposure of workers to the risks arising from physical agents (noise) Official Journal of the European Union, 15.2.2003, L 42/38.

15. Kaasik, A., Maasikmets, M. Concentrations of airborne particulate matter, ammonia and carbon dioxide in large scale uninsulated loose housing cowsheds in Estonia. Biosystems Engineering, 114:3, 2013, pp. 223-231, http://doi.org/10.1016/j.biosystemseng.2013.01.002.

16. Jacobson, L. D., Heber, A. J., Hoff, S. J. Zhang, Y., Beasley, D. B., Koziel, J. A., Hetchler, B. P. Aerial Pollutants Emissions from Confined Animal Buildings. [online] [25-04-2017]. Available at: https://www.ncsu.edu/airworkshop/Posters-j-k-l.pdf

17. Кристенсен Э. Х. Физиологиятруда // Энциклопедияпобезопасности и гигиенетруда. Т. 4, Ч. 1 “ Р - Ф “. Москва, Профиздат, 1987, 2713 р.

18. Jungbluth, T., Büscher, W., Krause, M. Technikierhaltung. Stuttgart. Verlag Eugen Ulmer, 2005, $304 \mathrm{p}$. 